\title{
História social de intelectuais de vanguarda
}

\author{
Social history of avant-garde intellectuals
}

MICELI, Sergio. Vanguardas em retrocesso: ensaios de história social e intelectual do modernismo latino-americano. São Paulo: Cia das Letras, 2012, 240 p.

\section{Bruno de Macedo Zorek}

bruno.zorek@gmail.com

Doutorando

Universidade Estadual de Campinas

Rua Canadá, 1000

82510-290 - Curitiba - PR

Brasil

Palavras-chave

História intelectual; Modernismos; Literatura.

Keywords

214

Intellectual history; Modernisms; Literature. 
Vanguardas em retrocesso, o mais recente livro de um dos herdeiros de Pierre Bourdieu, o sociólogo e professor da Universidade de São Paulo (USP) Sergio Miceli, é composto por uma série de reflexões sobre intelectuais argentinos e brasileiros. O principal objetivo do autor é revelar as conexões existentes entre os feitos estéticos e acadêmicos de seus personagens e os condicionantes sociais a que estavam sujeitos. Sua estratégia, desta vez, é comparar trajetórias estruturalmente semelhantes e contemporâneas entre si de intelectuais dos dois países em questão. Miceli parte do princípio de que é necessário problematizar a típica representação "sacralizada" dos indivíduos que investiga. Figuras como Jorge Luis Borges e Mário de Andrade, lideranças dos movimentos de que fizeram parte e alçados à condição de modelos de intelectuais, são geralmente celebrados por suas qualidades quase a-históricas de escritores puros, que estariam acima dos condicionantes sociais comuns a todos - sobretudo Borges. O gênio desses indivíduos teria Ihes permitido superar sua historicidade e desvincular suas obras das condições em que foram produzidas, como se fossem objetos nascidos única e exclusivamente da vontade criadora - obras universais, livres de quaisquer constrangimentos. Pelo menos, o apagamento dos vínculos sociais nas obras dos autores consagrados é um esforço comum de certa crítica literária que produz, na prática, um novo tipo de hagiografia. Em oposição a essa leitura, Miceli demonstra o quão imbricados são os trabalhos desses intelectuais à sociedade da qual fizeram parte. Além disso, o sociólogo desconstrói aqueles argumentos estetizantes que sacralizam a vida e o trabalho desses personagens. Para tanto, o autor entrelaça as inovações artísticas do modernismo brasileiro e das vanguardas argentinas às histórias de vida de seus membros, indicando como a posição familiar no espaço social, a situação patrimonial, a educação, a vinculação a grupos dirigentes, as redes de sociabilidade, as relações amorosas etc. estão completamente imiscuídas nas obras. As conclusões dessa análise explicam a provocação do título escolhido: Miceli convincentemente argumenta que as vanguardas literárias examinadas eram a voz artística de suas respectivas elites oligárquicas em decadência. Mesmo que não completamente cientes do que faziam, esses intelectuais eram caudatários, no campo cultural, dos interesses de grupos politicamente conservadores - sob a fachada da renovação estética se processavam práticas políticas regressivas. De fato, a própria condição de vanguarda artística, nesses casos, só pode ser entendida no contexto de reação das elites oligárquicas a seu próprio declínio, fruto das mudanças radicais pelas quais o Brasil e a Argentina passavam.

O livro é dividido em sete capítulos: no primeiro, Miceli faz uma leitura minuciosa da formação dos campos literários do Brasil e da Argentina nas décadas de 1920 e 1930; os dois seguintes são dedicados a Jorge Luis Borges - os pontos altos do livro; o quarto tem como personagem analisado a Mário de Andrade; o quinto é sobre Tarsila do Amaral e Ricardo Güiraldes; o sexto compara as trajetórias de Lasar Segall e Xul Solar; e o último, enfim, destoando do recorte artístico mantido até então, trata de Florestan Fernandes e de Gino Germani. Além disso, o volume é apresentado por um prólogo em que o sociólogo explicita as condições em que realizou a pesquisa. Foram dez anos de estudos, iniciados no invejável acervo de obras latino-americanas da biblioteca da Universidade de 
Stanford, nos Estados Unidos. O acesso privilegiado a essa bibliografia viabilizou a leitura de grande parte das produções das vanguardas argentinas. A coleta dos dados continuou na própria Argentina, em alguma medida facilitada pelos contatos frequentes com professores do país vizinho, sobretudo com os do chamado "grupo de Quilmes", liderados por Carlos Altamirano e bastante interessados nos estudos de história dos intelectuais. Os materiais sobre os brasileiros, evidentemente, não careceram do esforço internacional para serem coligidos.

No prólogo, Miceli procura construir uma unidade para os capítulos. Esse esforço é necessário tendo em vista que nenhum dos artigos foi escrito originalmente para o livro - todos são versões de trabalhos apresentados em outras ocasiões. Sua reunião em um único volume está baseada na semelhança entre o tipo de objeto, intelectuais, e a perspectiva de análise, comparação de trajetórias. Todavia, o título, apesar de inspirado, não consegue abarcar todas as discussões do livro. Vanguardas em retrocesso e mesmo o subtítulo, Ensaios de história social e intelectual do modernismo latino-americano, soam estranhos quando se pensa nos chamados inventores sul-americanos da sociologia "científica", analisados no último capítulo. Apesar de representarem um tipo de vanguarda - por conta de suas inovações nas pesquisas sociológicas -, nem Florestan Fernandes, nem Gino Germani podem ser associados a interesses políticos regressistas. Da mesma forma, o adjetivo "modernista" não se encaixa com precisão na descrição desses intelectuais.

O primeiro capítulo estabelece as características estruturais dos campos 216 de produção intelectual do Brasil e da Argentina. Diferentemente dos países centrais do capitalismo, nas primeiras décadas do século $X X$, os países periféricos não contavam com uma efetiva autonomização das figuras do "intelectual" e do "artista" em relação às demandas do campo político. Miceli insiste no fato de que a produção intelectual nesses países só pôde florescer graças ao apadrinhamento dos escritores por membros das elites. No Brasil, foram os próceres partidários os principais mediadores entre os poderes político e econômico e a produção cultural. Já na Argentina, foram os grandes empresários da imprensa portenha os mecenas mais comuns dos intelectuais. Essa relação de simbiose entre as vanguardas artísticas e as elites dirigentes fez com que, em um só movimento, experimentos estéticos renovadores sintetizassem posicionamentos políticos conservadores. É nesse sentido que Miceli enxerga no nacionalismo das vanguardas uma importante chave para a leitura de seus comprometimentos políticos. As "escolhas" do criollismo argentino e do barroco brasileiro como solos férteis para os experimentos estéticos novidadeiros construíam um passado mitificado e buscavam em uma cultura popular autóctone os cenários para a positivação dos valores tradicionais então ameaçados. As obras desses intelectuais se opunham à presença imigrante e à recomposição das elites dirigentes - de fato, processos incontornáveis, que destruíam a ordem estabelecida naquele momento. Tanto foi assim que essas vanguardas não resistiram às transformações políticas que afetaram o Brasil e a Argentina a partir de 1930. O rearranjo das forças políticas implicou uma nova configuração dos campos (ou protocampos) intelectuais, mostrando como a dependência desses últimos em relação às primeiras era ainda muito forte. 
Nos três capítulos seguintes, Miceli analisa os dois principais nomes de ambas as vanguardas consideradas: Jorge Luis Borges e Mário de Andrade. Ambos possuem peculiaridades em suas trajetórias que os diferenciam dos demais intelectuais de sua geração. Os dois tiveram uma educação diferenciada. Borges, em função das viagens médicas do pai pela Europa, dominou diversas línguas estrangeiras, o que Ihe permitiu conhecer diferentes estilos literários e transitar por eles com significativa facilidade. Mário foi o único escritor modernista da primeira geração que não cursou Direito na Faculdade do Largo de São Francisco. Sua passagem pelo curso de Contabilidade e o diploma do Conservatório Dramático e Musical foram os trunfos que lhe forneciam um capital cultural distinto. Tanto um quanto o outro nasceram em famílias com uma situação patrimonial comprometida e viveram dramas familiares marcantes ainda muito jovens: a cegueira do pai de Borges, a perda do irmão caçula de Mário. Isso significou para ambos a antecipação de experiências da vida adulta e Ihes imprimiu uma espécie de sentimento de urgência, dada a situação periclitante que se desenhava em seus respectivos clãs domésticos. Além disso, Mário e Borges viram negados para si os modelos masculinos tradicionais das elites, pois suas famílias não Ihes davam condições de assumir uma carreira política, a condição de proprietário ou o papel de chefe de família. O celibato, "opção" adotada por ambos, foi a estratégia possível para, em alguma medida, fugir das vicissitudes que o "destino" Ihes impunha.

Essas características de suas trajetórias os colocavam em posições únicas em relação aos seus pares. Eles combinavam uma situação material precária, que Ihes deixava pouquíssimas alternativas de carreira, com um capital cultural considerável e diferenciado, que os privilegiava frente à concorrência. Assim, a aposta de todas as suas fichas na carreira intelectual parecia a ambos a melhor, se não a única, escolha a ser feita. Somavam-se a isso, no caso de Borges, as redes de sociabilidade em que estava envolvido, principalmente por conta dos amigos da família. Borges havia estado em contato com vários escritores da geração de seu pai, o que lhe abriu as portas para a carreira intelectual. Mário de Andrade, ao contrário, beneficiou-se mais das transformações que se processavam em São Paulo e que criavam novas oportunidades a todo momento do que de contatos herdados. Na verdade, não possuía praticamente nenhum capital familiar que Ihe facilitasse a inserção no universo intelectual. Por isso, sua posição foi construída quase em oposição aos estilos intelectuais dominantes, fazendo de Mário um tipo único de intelectual; ao passo que Borges seguiu os estilos tradicionais de intelectuais portenhos. Mas ambos, no final das contas, construíram suas posições de destaque em meio a vanguardas que representavam elites decadentes. Por isso, nas palavras de Miceli: "Borges e Mário são os heróis lendários da crise do poder oligárquico, os derradeiros porta-vozes de um mundo em desmonte, nutridos por um estilo de vida e de pensamento golpeado de morte" (MICELI 2012, p. 122).

O capítulo dedicado à dupla Tarsila do Amaral e Ricardo Güiraldes e o seguinte, cujos personagens são Lasar Segall e Xul Solar, são comparações de artistas que ocuparam posições estruturalmente semelhantes nos campos 
artísticos brasileiro e argentino. Güiraldes e Tarsila eram membros da última geração de intelectuais e artistas latino-americanos que não precisavam de sua atividade para garantir sua reprodução social. Ambos eram filhos da nata das elites dirigentes locais e herdeiros de fortunas significativas. Em situação muito diferente estavam Lasar Segall e Xul Solar, pintores que amadureceram na Europa e, somente depois de artisticamente formados, adotaram os países periféricos como seus. Os dois sofreram duras hostilidades contra seu estabelecimento no Velho Mundo e, quando vieram para o Novo, precisaram adaptar seus estilos aos gostos do mercado local. Tarsila e Güiraldes tiveram uma formação marcada pela sociabilidade tranquila das elites agrárias sul-americanas e por viagens privilegiadas pela Europa, onde tomaram contato com o mundo artístico de Paris. Em função da segurança material de que desfrutavam, não se preocuparam em firmar um caminho artístico consistente desde cedo. Foi somente depois de seus casamentos que ambos se afirmaram nas vanguardas. A fase mais criativa e importante de Tarsila coincide com sua relação com Oswald de Andrade, enquanto Güiraldes se torna um escritor sistemático graças ao apoio de sua esposa, Adelina del Carril. Foi pela combinação de capitais que os dois se tornaram nomes importantes nos cenários artísticos. Já Xul Solar e Lasar Segall se estabeleceram nas cenas argentina e brasileira em função das transformações das elites dirigentes, que passaram a incorporar elementos imigrantes em seus quadros. O porte artístico consolidado de ambos, por conta dos anos de treinamento técnico e estético na Europa, transformava-os em 218 personagens interessantes para os novos membros das elites, que procuravam cooptá-los com vistas à construção de seu capital simbólico. Em contrapartida, os pintores adaptavam seus estilos aos das vanguardas locais, aproximando, assim, os gostos ainda em processo de estabelecimento das novas elites dos gostos estabelecidos das elites tradicionais.

No sétimo e último capítulo do livro, Miceli compara as trajetórias de Florestan Fernandes e de Gino Germani, os inventores da "sociologia científica" respectivamente no Brasil e na Argentina. Ambos são apresentados como desprovidos dos capitais econômicos e sociais mais apreciados nos campos intelectuais dos países em que viviam. Nos ambientes letrados em questão, duas das habilidades que caracterizavam os intelectuais mais respeitados eram a erudição literária e o domínio de uma escrita esteticamente trabalhada. A sociologia daquele momento era uma disciplina secundária, de parco interesse para os grupos intelectualmente dominantes, que viam o ensaio como o gênero de maior prestígio. Entretanto, a expansão universitária e financiamentos de instituições estrangeiras acabaram criando espaço para o desenvolvimento de um tipo de pesquisa, de molde cientificista e monográfico, paralelo aos interesses dominantes nos respectivos campos intelectuais. Florestan Fernandes e Gino Germani apostaram suas fichas nessa carreira alternativa, a única que poderia consagrá-los, dado que eram proibidas para eles, por conta das condições sociais de suas origens, as carreiras intelectuais tradicionais. Nesse sentido, a história da Sociologia como disciplina é indissociável da história de seus "inventores", da mesma forma que os feitos artísticos só podem ser entendidos em conjunção 
com a história de vida dos próprios artistas. O princípio por trás dos estudos de Sergio Miceli é o de que não há sublimação da história: toda e qualquer ação social - intelectual, artística ou outra - precisa ser localizada no contexto de sua produção, sem o qual seu entendimento se torna inviável, quando não politicamente insidioso. 